\title{
KAJIAN PERUBAHAN KETERSEDIAAN RUANG TERBUKA HIJAU DI KECAMATAN TEMBALANG, KOTA SEMARANG, BERBASIS INTERPRETASI CITRA SATELIT
}

\author{
R. Nugraha ${ }^{a}$, S. Rahayu ${ }^{b}$ \\ a Universitas Diponegoro, Indonesia, email: anakpakam@gmail.com \\ ${ }^{b}$ Universitas Diponegoro, Indonesia, email: sri.yksmg@yahoo.com
}

\begin{tabular}{l} 
Article Info; \\
Received: \\
3 March 2014 \\
Received in revised \\
form: 10 March 2014 \\
Accepted: \\
26 March 2014 \\
Available Online: \\
1 April 2014 \\
\hline
\end{tabular}

Keywords:

GIS, Satellite

Imagery, Green

space

Info Artikel;

Diterima:

3 Maret 2014

Hasil Revisi :

10 Maret 2014

Disetujui:

26 Maret 2014

Publikasi On-Line:

1 April 2014

Kata kunci:

Sistem Informasi

Geografis, Citra

Satelit, RTH

\begin{abstract}
Increasing the number of population in the District Tembalang, Semarang in 19912010 has implications for the increase of space for settlement and infrastructure that impact on the reduced number of green space. District Tembalang needs special attention, especially in the provision of green space because it is one of the fast developing area in the Semarang. Based on the above problems, the research question arises, how changes in the availability of green space in the District Tembalang? The purpose of this study is to assess the changes in availability of green space in the District Tembalang, Semarang during the period of 12 years i.e from 1999 till 2011. This study uses remote sensing techniques by performing image interpretation using ArcGIS 9.3 software and using data satellite imagery of District Tembalang 1999 and Ikonos Satellite Imagery 2011. Based on the analysis, an area of green space in the District Tembalang in 1999 was 3214, 86 ha and in 2011 was 3017,73 ha. The decrease of green space area during the period of 1999-2011 is $197.13 \mathrm{Ha}$. One of the recommendations of this study is the need to control the development activity, according to the land use planning based on RDTRK (urban planning documents) Semarang to maintain the availability of green space
\end{abstract}

\section{PENDAhUluAN}

Ruang terbuka hijau adalah sebentang lahan terbuka tanpa bangunan yang mempunyai ukuran, bentuk dan batas geografis tertentu dengan status penguasaan apapun, yang di dalamnya terdapat tetumbuhan hijau berkayu dan tahunan (perennial woody plants), dengan pepohonan sebagai tumbuhan penciri utama dan tumbuhan lainnya (perdu, semak, rerumputan, dan tumbuhan penutup tanah lainnya), sebagai tumbuhan pelengkap, serta benda-benda lain yang juga sebagai pelengkap 
dan penunjang fungsi RTH yang bersangkutan oleh Purnomohadi (2006). Pada 30 tahun terakhir luas RTH diperkotaan berkurang dengan sangat signifikan. Berkurangnya luas RTH di perkotaan salah satunya disebabkan oleh jumlah penduduk diperkotaan yang terus meningkat. Untuk lebih jelas melihat peningkatan jumlah penduduk di Kecamatan Tembalang dapat dilihat pada Gambar 1 berikut.

Gambar 1. Grafik Peningkatan Jumlah Penduduk Tembalang (BPS, 2011)

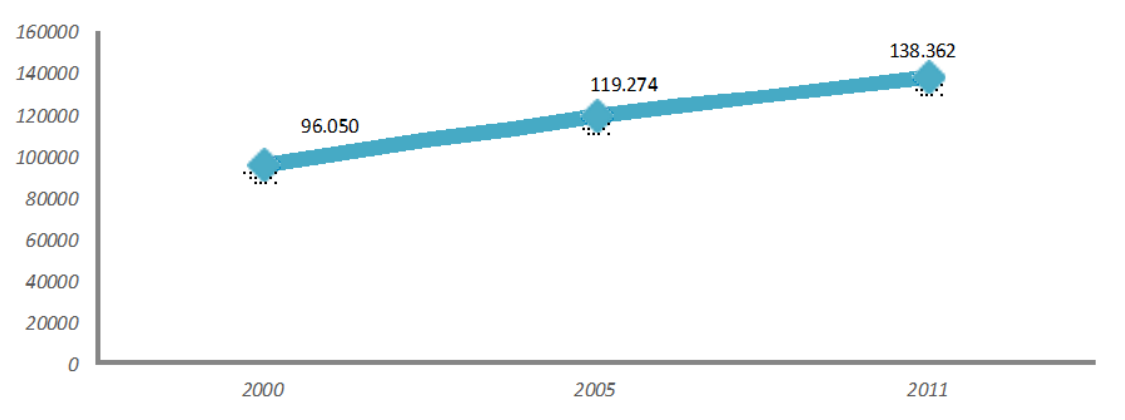

Peningkatan jumlah penduduk yang terjadi di Kecamatan Tembalang dikarenakan terdapat kecendrungan pekembangan Kota Semarang ke arah selatan yang menjangkau kawasan Tembalang dan sekitarnya. Faktor pendorong berasal dari kawasan pusat Kota Semarang yang semakin padat dan beban yang ditanggungnya pun semakin berat. Sedangkan faktor penarik berasal dari Kawasan Tembalang berupa lahan-lahan yang masih dapat dimanfaatkan untuk kegiatan budidaya tanpa meninggalkan aspek pelestarian lingkungan (RDTRK Semarang BWK VI 2000-2010). Beragamnya aktifitas dan semakin bertambahnya penduduk pendatang di Kecamatan Tembalang akan memberi implikasi terhadap meningkatnya kebutuhan ruang untuk permukiman serta sarana prasarana penunjangnya. Hal ini berarti bahwa dengan bertambahnya jumlah penduduk Kecamatan Tembalang akan bertambah pula ruang terbangun yang akan semakin menggeser RTH di Kecamatan Tembalang jika pembangunan tidak dilakukan dengan perencanaan yang baik. Oleh sebab itu, sebagai kecamatan yang sedang berkembang, Kecamatan Tembalang perlu mendapat perhatian khusus terutama dalam penyediaan RTH agar dapat terwujud keseimbangan dalam pembangunan, hal ini sangat beralasan karena Berdasarkan RDTRK Semarang BWK VI tahun 2000-2010 Kecamatan Tembalang difungsikan untuk perumahan yaitu sebagai penampung limpahan penduduk dari pusat Kota Semarang.

Pengembangan permukiman kota berupa perumahan baru (real estate) di Kecamatan Tembalang terdapat di Kelurahan Meteseh, Kelurahan Sendangmulyo, sebagian Kelurahan Jangli, sebagian Kelurahan Kedungmundu, sebagian Kelurahan Sambiroto, dan sebagian Kelurahan Mangunharjo. Berdasarkan dari uraian permasalahan di atas, dapat diketahui bahwa RTH sangat penting bagi keberlanjutan suatu kota dalam hal ini khususnya di Kecamatan Tembalang Kota Semarang, maka dari itu timbul pertanyaan penelitian (research question) yang mendasari kegiatan penelitian ini, yaitu "Bagaimana perubahan ketersediaan RTH di Kecamatan Tembalang Kota Semarang selama kurun waktu 12 tahun yaitu tahun 1999 sampai dengan tahun 2011?“. Untuk menjawab pertanyaan tersebut maka perlu dilakukan penelitian tentang ketersediaan RTH di Kecamatan Tembalang kota Semarang selama periode 12 tahun yaitu dari tahun 1999 sampai tahun 2011 di Kecamatan Tembalang Kota Semarang. Tujuan yang ingin dicapai dalam penelitian ini adalah untuk mengkaji perubahan ketersediaan RTH di Kecamatan Tembalang Kota Semarang selama periode 12 tahun yaitu dari tahun 1999 sampai tahun 2011.

\section{DATA DAN METODE}

Ruang terbuka hijau merupakan ruang yang direncanakan karena kebutuhan akan tempat-tempat pertemuan dan aktivitas bersama di udara terbuka. Ruang terbuka adalah ruang yang bisa diakses oleh masyarakat baik secara langsung dalam kurun waktu terbatas maupun secara tidak langsung dalam kurun waktu tidak tertentu. Ruang terbuka itu sendiri bisa berbentuk jalan, trotoar, ruang terbuka hijau seperti taman kota, hutan dan sebagainya oleh Hakim dan Utomo (2004). Manfaat RTH diantaranya adalah untuk identitas kota, nilai estetika, penyerap karbondioksida, pelestarian air tanah, penahan angin, ameliorasi iklim, habitat dan kehidupan liar. Berdasarkan Peraturan Daerah Kota Semarang No.7 tahun 2010 Tentang Penataan Ruang Terbuka Hijau (RTH) jenis penataan RTH di Kota Semarang terdiri atas RTH Kawasan Hutan 
Lindung, RTH Kawasan Taman Hutan Raya, RTH Kawasan Rawan Bencana, RTH Kawasan Pantai Berhutan Bakau, RTH Kawasan Sempadan Pantai, RTH Kawasan Sempadan Sungai, RTH Kawasan Sempadan Mata Air, RTH Kawasan Sempadan Waduk, RTH Kawasan Pertanian Lahan Basah, RTH Kawasan Pertanian Lahan Kering, RTH Kawasan Perikanan/ Tambak, RTH Kawasan Hutan Produksi, RTH Kawasan Permukiman, RTH Kawasan Perkantoran dan Fasilitas Umum, RTH Kawasan Perdagangan dan Jasa Komersial, RTH Kawasan Pendidikan, RTH Kawasan Industri, RTH Kawasan Wisata, Rekreasi dan Olah Raga, RTH Kawasan Pemakaman, RTH Pertamanan dan Lapangan, RTH Kawasan Khusus Militer, RTH Kawasan Terminal, RTH Kawasan Stasiun Kereta Api, RTH Kawasan Pelabuhan Laut, RTH Kawasan Bandar Udara, RTH Jalur Jalan, RTH Jalur Sempadan Rel Kereta Api, RTH Jalur Sambungan Udara Tegangan Tinggi (SUTT) dan Sambungan Udara Tegangan Ekstra Tinggi (SUTET); dan RTH Taman Atap (Roof Garden).

Metode yang digunakan dalam studi ini adalah metode kuantitatif dengan menggunakan penginderaan jauh. Metode ini sebagai metode ilmiah yang konkrit/empiris, obyektif, terukur, rasional, dan sistematis. Metode ini menggunakan data-data penelitian berupa angka-angka dan analisis menggunakan statistik (Sugiyono, 2008). Penginderaan jauh disingkat inderaja, berasal dari bahasa Inggris yaitu remote sensing. Pada awal perkembangannya, inderaja hanya merupakan teknik yang dikembangkan untuk memperoleh data di permukaan bumi. Akan tetapi, seiring dengan perkembangan iptek, ternyata inderaja seringkali berfungsi sebagai suatu ilmu karena sangat besar kemanfaatannya. Menurut Lillesand dan Kiefer (1998), Penginderaan Jauh adalah ilmu dan seni untuk memperoleh informasi tentang obyek, daerah, atau gejala dengan jalan menganalisis data yang diperoleh dengan menggunakan alat tanpa kontak langsung terhadap obyek, daerah, atau gejala yang dikaji. Penginderaan jauh akan bergantung pada panjang energi gelombang elektromagnetik sedangkan Gelombang elektromagnetik bervariasi membentuk panjang gelombangnya. Cahaya matahari berperan dalam penggunaan sensor padapengideraan jauh. Sebagian sensor dapat mendeteksi energi yang diemisikan bumi oleh Janssen dan Huurneman (2001).

Data yang digunakan adalah data Citra Ikonos dan foto udara. Sejak diluncurkan pada September 1999, citra satelit bumi, Space Imaging Ikonos menyediakan data citra yang akurat, dimana menjadi standar untuk produk-produk data satelit komersil yang beresolusi tinggi. Ikonos memproduksi citra 1-meter hitam dan putih (pankromatik) dan citra 4-meter multispektral (red, blue, green dan near-infrared) yang dapat dikombinasikan dengan berbagai cara untuk mengakomodasikan secara luas aplikasi citra beresolusi tinggi oleh Space Imaging (2004). Disamping mempunyai kemampuan merekam citra multispetral pada resolusi 4 meter, Ikonos dapat juga merekam obyek-obyek sekecil satu meter pada hitam dan putih. sebagai salah satu data penginderaan jauh Citra Foto Udara mampu menyajikan gambaran mirip wujud dan letak sebenarnya di lapangan dan dapat dilihat pola keruangannya (Sutanto, 1987). Segala hasil perekaman foto udara ini berpuluh hingga beribu pasang foto udara tergantung dari tujuan pemetaan dan perekaman selalu disimpan dalarn media penyimpanan. Hal ini selalu dilakukan karena pemotretan obyek, daerah atau fenomena yang dikaji itu selalu dilakukan berkala dan tidak saal itu juga. Menurut Estes dan Simonett (1975) interpretasi citra merupakan perbuatan mengkaji foto udara atau citra dengan maksud untuk mengidentifikasi objek dan menilal arti pentingnya objek tersebut. Untuk melakukan interpretasi citra maupun foto udara digunakan kreteria interpretasi, yaitu terdiri atas rona atau warna, ukuran, bentuk, tekstur, pola, bayangan, situs, dan asosiasi.

Selain dengan penginderaan jauh, interpretasi juga dibantu dengan perangkat lunak SIG. Aronoff menjelaskan dalam Prahasta (2009: 116) sistem informasi geografis (Geographic Information System) adalah sistem yang berbasis komputer yang digunakan untuk menyimpan dan memanipulasi data mengenai informasi geografis. SIG dirancang untuk mengumpulkan, menyimpan, dan menganalisis objekobjek dan fenomena di suatu lokasi geografis merupakan kerakteristik yang penting untuk dianalisis. Dengan demikian, SIG merupakan sistem komputer yang memiliki empat kemampuan dalam menangani data yang bereferensi geografis seperti masukan, manajemen data (penyimpanan dan pemanggilan data), analisis, dan manipulasi serta keluaran. Pengumpulan data primer dilakukan dengan cara melakukan tinjauan dan pengumpulan data secara langsung dari kondisi yang ada di lapangan. Perolehan data primer dalam penelitian ini adalah berupa observasi di lapangan. Pelaksanaan teknik pengumpulan data dengan melalui observasi ini yaitu dengan melakukan pengamatan secara langsung terhadap obyek wilayah studi yaitu RTH Kecamatan Tembalang. 


\section{HASIL DAN PEMBAHASAN}

Berdasarkan hasil interpretasi citra menggunakan Citra Foto Udara Kecamatan Tembalang tahun 1999, RTH Kecamatan Tembalang memilki luas 3.214,86 Ha, RTH mendominasi luas persentase penggunaan lahan di Kecamatan Tembalang, yaitu sebesar $80,55 \%$. Kemudian dari sisa penggunaan lahan selain RTH yaitu seluas $264,43 \mathrm{Ha}$ atau 6,63\% digunakan untuk penggunaan lahan bangunan dan 511,73 atau $12,82 \%$ digunakan untuk penggunaan lahan lainnya (tanah longsor, tanah kosong, fasilitas umum, perkantoran, pabrik, dan jalan raya). Untuk lebih jelas luas tata guna lahan Kecamatan Tembalang tahun 1999 (ha) dapat di lihat pada Gambar 2 dan hasil interpretasi citra satelit di Gambar 3 dan Tabel 1.

Gambar 2.Diagram Luasan RTH di Kecamatan Tembalang Tahun 1999 (Analisis, 2013)

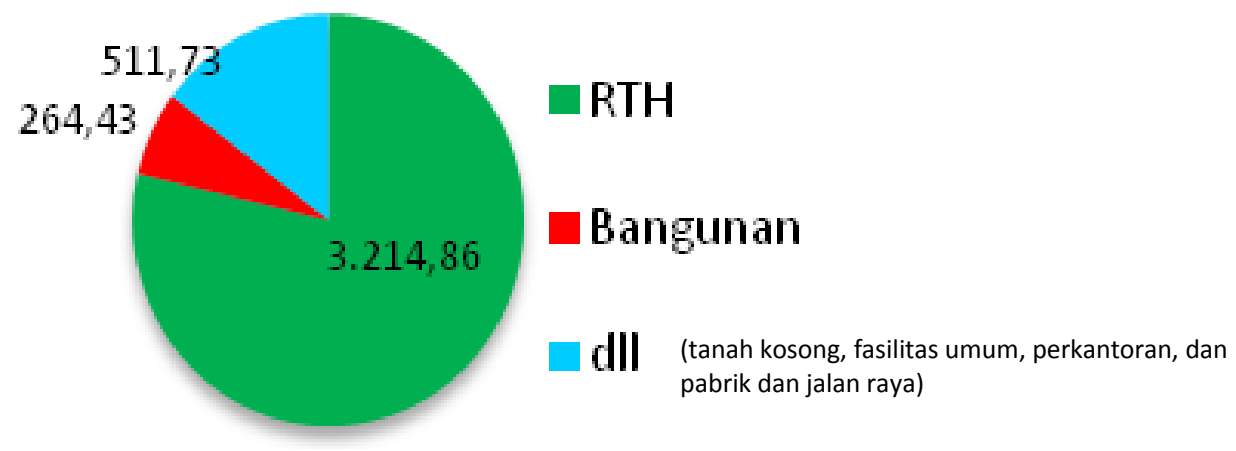

Gambar 3. Hasil Interpretasi dan Jenis RTH tahun 1999, ( Analisis, 2013)

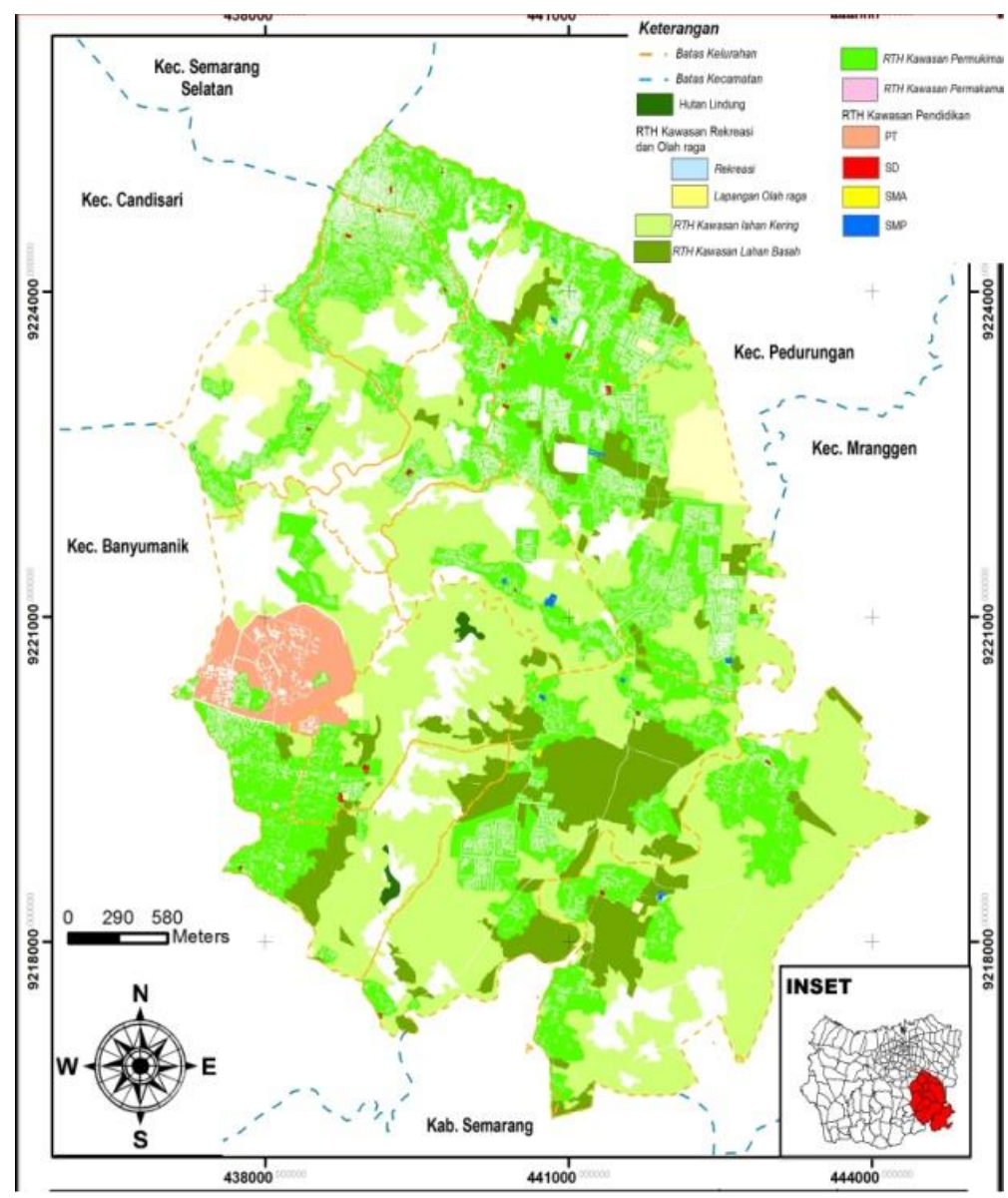


Tabel 1. Luas RTH Hasil Interpretasi dan Jenis RTH tahun 1999 (Analisis, 2013)

\begin{tabular}{lccc} 
No. & Jenis RTH & \multicolumn{2}{c}{ Tahun 1999 } \\
\cline { 3 - 4 } & & Luas RTH & Persentase (\%) \\
\hline $\mathbf{2}$ & RTH kawasan pertanian lahan basah & 378.05 & $9,47 \%$ \\
\hline $\mathbf{3}$ & RTH kawasan pertanian lahan kering & $1.510,8$ & $37,84 \%$ \\
\hline $\mathbf{5}$ & RTH kawasan permukiman & $1.033,21$ & $25,91 \%$ \\
\hline $\mathbf{5}$ & RTH kawasan pendidikan & 112,67 & $2,82 \%$ \\
\hline
\end{tabular}

Dari hasil tersebut diperoleh RTH terluas adalah RTH kawasan pertanian lahan kering seluas 1.510,8 ha, kemudian terluas kedua adalah RTH kawasan permukiman seluas 1.033,21 ha, terluas ketiga adalah RTH kawasan pertanian lahan basah seluas 378,05 ha, terluas keempat adalah RTH kawasan pendidikan seluas 112,67 Ha, terluas kelima adalah RTH kawasan rekerasi dan olah raga seluas 90,10 ha, dan terluas keenam atau terluas terkecil adalah RTH kawasan pemakaman seluas 90,03 ha. Sementara itu, untuk RTH kawasan hutan lindung pada tahun 1999 di Kecamatan Tembalang tidak ditemukan karena penggunaan lahan pada kawasan lindung telah beralih fungsi menjadi penggunaan lahan non RTH kawasan hutan lindung seperti pertanian lahan kering dan pertanian lahan basah.

Selanjutnya, berdasarkan hasil interpretasi citra menggunakan Citra Ikonos Kecamatan Tembalang tahun 2011, RTH Kecamatan Tembalang memiliki luas 3.017,73 ha dari total luas Kecamatan Tembalang yaitu 3.991,02 ha, RTH mendominasi luas persentase penggunaan lahan di Kecamatan Tembalang pada tahun 2011 yaitu sebesar 75,62\%. Kemudian dari sisa penggunaan lahan selain RTH yaitu seluas 419,81 ha atau $10,52 \%$ digunakan untuk penggunaan lahan bangunan dan 553,48 ha atau $13,86 \%$ digunakan untuk penggunaan lahan lainnya (tanah longsor, tanah kosong, fasilitas umum, perkantoran, dan pabrik, dan jalan raya). Untuk lebih jelas luas tata guna lahan Kecamatan Tembalang tahun 2011 dapat di lihat pada Gambar 4 dan hasil interpretasi pada Gambar 5 dan Tabel 2.

Gambar 4. Diagram Luas RTH di Kecamatan Tembalang Tahun 2011 (Analisis, 2013)

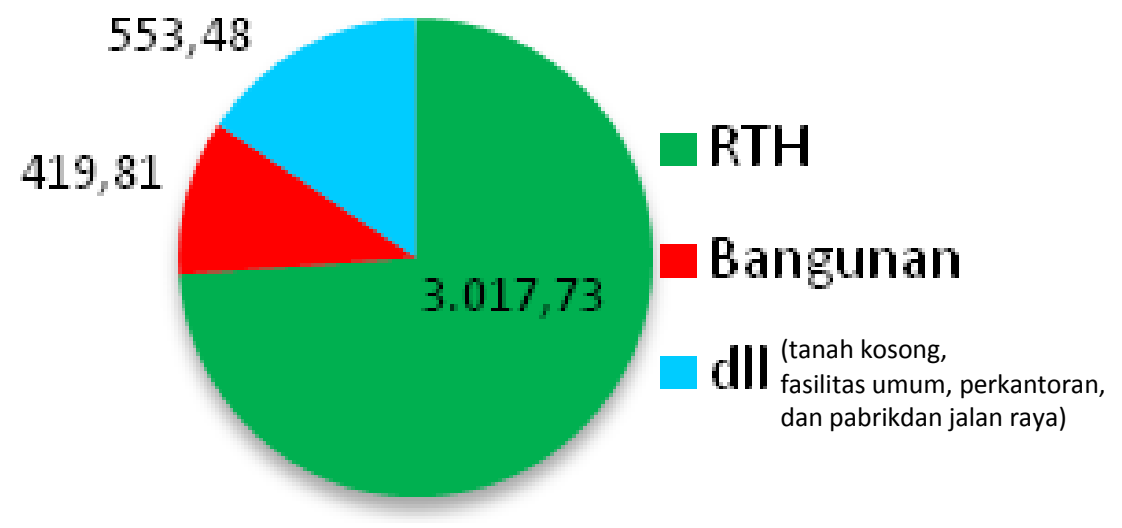


Gambar 5 . Hasil Interpretasi Citra Satelit tahun 2011 (Analisis, 2013)

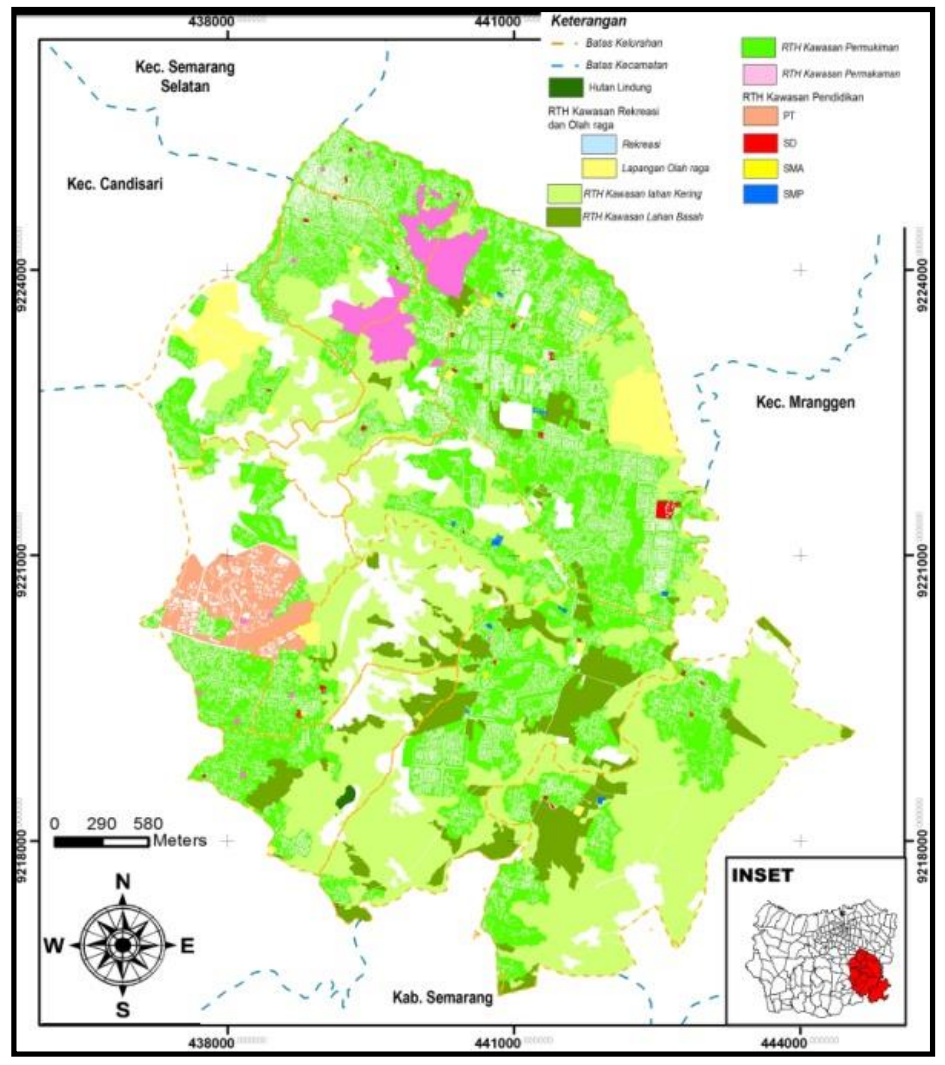

Tabel 2. Luas RTH Hasil Interpretasi dan Jenis RTH tahun 2011 (Analisis, 2013)

\begin{tabular}{cccc}
\hline & & & Tahun 2011 \\
No. & Jenis RTH & Luas RTH & Persentase \\
\cline { 3 - 4 } $\mathbf{1}$ & RTH kawasan pertanian lahan basah & 265,35 & $6,65 \%$ \\
\hline 2 & RTH kawasan pertanian lahan kering & $1.271,08$ & $31,86 \%$ \\
\hline 3 & RTH kawasan permukiman & $1.187,08$ & $29,74 \%$ \\
\hline 4 & RTH kawasan pendidikan & 107,24 & $2,69 \%$ \\
\hline 5 & RTH kawasan rekreasi dan olah raga & 96,38 & $2,41 \%$ \\
\hline 6 & RTH kawasan pemakaman & 90,6 & $2,27 \%$ \\
\hline
\end{tabular}

Berdasarkan hasil tersebut, RTH terluas adalah RTH kawasan pertanian lahan kering seluas 1.271,08 Ha, kemudian terluas kedua adalah RTH kawasan permukiman seluas 1.187,08 Ha, terluas ketiga adalah RTH kawasan pertanian lahan basah seluas 265,35 Ha, terluas keempat adalah RTH kawasan pendidikan seluas 107,24 Ha, terluas kelima adalah RTH kawasan permukiman seluas 90,6 $\mathrm{Ha}$, dan terluas keenam atau terluas terkecil adalah RTH kawasan rekreasi dan olah raga seluas 90,38 Ha. Sementara itu, untuk RTH kawasan hutan lindung pada tahun 2011 di Kecamatan Tembalang tidak ditemukan karena penggunaan pada kawasan lindung telah beralih fungsi menjadi penggunaan lahan non RTH kawasan hutan lindung seperti pertanian lahan kering dan pertanian lahan basah.

Setelah interpretasi data citra dilakukan, selanjutnya dilakukan analisis overlay raster untuk mengetahui perubahan luasan RTH. Dari hasil analisis tersebut, RTH di Kecamatan Tembalang pada analisis tahun 1999 adalah $80 \%(3.214,86)$ ha dari luas Kecamatan Tembalang dan RTH Kecamatan Tembalang pada tahun 2011 memiliki luas 75 \% (3.017,73 ha) dari luas Kecamatan Tembalang. Hal ini menunjukkan selama kurun waktu 1999-2011 RTH di Kecamatan Tembalang mengalami penurunan seluas 197,13 Ha atau 
berkurang 4,93\% dari luas RTH tahun 1999. Untuk lebih jelasnya mengenai perubahan ketersediaan setiap RTH di Kecamatan Tembalang selama kurun waktu tahun 1999-2011 dapat di lihat pada Tabel 3 berikut.

Tabel 3. Perubahan Luas RTH dari 1999-2011 (Analisis, 2013)

\begin{tabular}{|c|c|c|c|}
\hline \multirow[t]{2}{*}{ No. } & \multirow[b]{2}{*}{ Jenis RTH } & \multicolumn{2}{|c|}{ Hasil overlay } \\
\hline & & Luas Perubahan RTH & $\begin{array}{l}\text { Persentase } \\
\text { (\%) }\end{array}$ \\
\hline 1 & $\begin{array}{c}\text { RTH kawasan pertanian lahan } \\
\text { basah }\end{array}$ & $-112,7$ & $-2,82 \%$ \\
\hline 2 & $\begin{array}{c}\text { RTH kawasan pertanian lahan } \\
\text { kering }\end{array}$ & $-239,72$ & $-5,98 \%$ \\
\hline 3 & RTH kawasan permukiman & 153,87 & $3,83 \%$ \\
\hline 4 & RTH kawasan pendidikan & $-5,43$ & $-0,13 \%$ \\
\hline 5 & $\begin{array}{c}\text { RTH kawasan rekreasi dan olah } \\
\text { raga }\end{array}$ & 6,28 & $0,15 \%$ \\
\hline 6 & RTH kawasan pemakaman & 0,57 & $0,02 \%$ \\
\hline & Jumlah & $-197,13$ & $-4,93 \%$ \\
\hline
\end{tabular}

Dari hasil tersebut dapat diketahui bahwa secara keseluruhan RTH di Kecamatan Tembalang selama kurun waktu tahun 1999-2011 mengalami penurunan luas 197,13 Ha dengan RTH yang mengalami penurunan luas adalah RTH kawasan pertanian lahan basah, dan RTH yang mengalami peningkatan luas adalah RTH kawasan permukiman. Untuk RTH yang mengalami penurunan paling luas adalah RTH kawasan pertanian lahan kering yaitu seluas $239,72 \mathrm{Ha}$, sedangkan untuk RTH yang mengalami peningkatan paling luas adalah RTH kawasan permukiman yaitu seluas 153,87 Ha.

Berkurangnya luas RTH tersebut dikarenakan alih fungsi RTH lebih luas dibandingkan dengan luas pertambahan RTHnya, sedangkan meningkatnya luas RTH tersebut dikarenakan sebaliknya yaitu alih fungsi RTH yang lebih kecil dibandingkan dengan luas pertambahan RTH. Untuk lebih jelas, hasil analisis alih fungsi RTH di Kecamatan Tembalang tahun 1999-2011dapat dilihat pada Gambar 6.

Gambar 6 . Hasil analisis alih fungsi RTH tahun 2011 (Analisis, 2013)

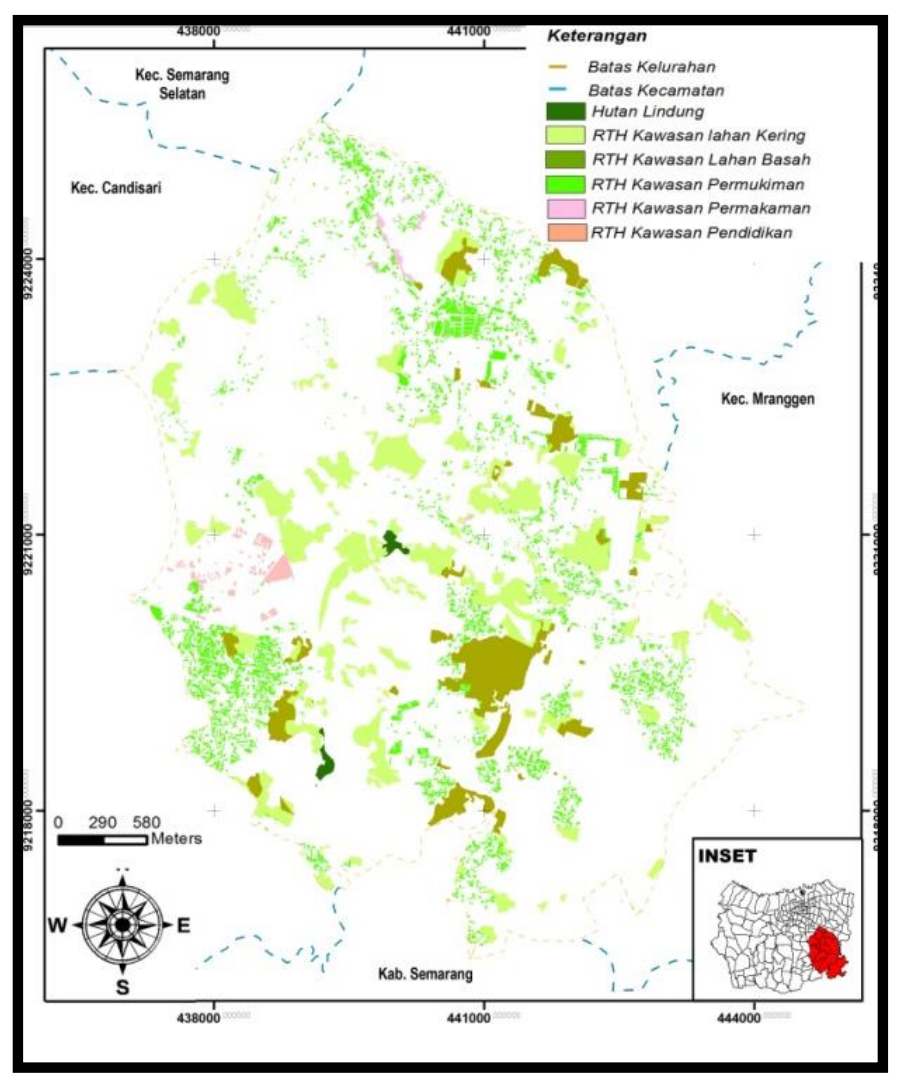




\section{KESIMPULAN}

Selama kurun waktu tahun 1999-2011 RTH di Kecamatan Tembalang didominasi oleh RTH kawasan pertanian lahan kering dengan luas 1.510,80 ha pada tahun 1999 dan seluas 1271,08 ha pada tahun 2011 yang sebagian besar terdapat di Kelurahan Rowosari. Terjadi penurunan luas RTH selama kurun waktu tahun 1999-2011 di Kecamatan Tembalang seluas 197,13 ha yang sebagian besar terdapat di Kelurahan Meteseh dengan luas 59 ha. Sementara itu, pertambahan RTH paling luas adalah RTH kawasan permukiman yang mengalami pertambahan seluas 262,86 ha yang sebagian besar terdapat di Kelurahan Sendangmulyo dengan luas 69,46 ha. RTH di Kecamatan Tembalang yang tidak mengalami perubahan selama kurun waktu tahun 1999-2011 adalah seluas 2.607,63 ha yang sebagian besar terdapat di Kelurahan Rowosari dengan luas 375,69 ha.

Dari hasil tersebut, penataan ruang Kecamatan Tembalang pada masa mendatang harus lebih memprioritaskan atau memperketat aturan terhadap kawasan lindung di Kecamatan Tembalang agar kawasan lindung di Kecamatan Tembalang dapat terwujud, karena dengan adanya kawasan lindung maka akan ada vegetasi yang mampu menjaga kepentinngan hidrologi, yaitu tata air dan dapat menghilangkan pengaruh topografi terhadap erosi dapat mencegah terjadinya banjir besar. Kegiatan pembangunan di Kecamatan Tembalang harus lebih mengarah pada usaha menjaga kelestarian RTH agar dapat terwujud keseimbangan dalam pembangunan, hal ini sangat beralasan karena Berdasarkan RDTRK Semarang BWK VI Kecamatan Tembalang difungsikan untuk perumahan yaitu sebagai penampung limpahan penduduk dari pusat Kota Semarang.

\section{DAFTAR PUSTAKA}

Estes, JE, Simonett, DS. 1975. Chapter 14: Fundamentals of image interpretation, in R.G. Reeves (Ed.), Manual of Remote Sensing, Vol. II, Falls Church: American Society of Photogrammetry, pp. 8691076.

Janssen, L.F.L and Huurneman C.G. 2001. Principles of Remote Sensing. ITC Educational Texbooks Series. ITC, Enshede, Netherlands.

Lillesand dan Kiefer. 1998. Penginderaan Jauh dan Interpretasi Citra Penginderaan Jauh, Yogyakarta: Gadjah mada University, Terjemahan Peraturan Menteri Dalam Negeri Nomor 1 tahun 2007 Tentang Penataan Ruang Terbuka Hijau Kawasan Perkotaan.

Perda Kota Semarang No.7 Tahun 2010 Tentang Ruang Terbuka Hijau.

Prahasta, Eddy. 2009. Sistem Informasi Geografis Konsep-Konsep Dasar (Perspektif Geodesi \& Geomatika), Informatika: Bandung.

Purnomohadi, Ning. 2006. Ruang Terbuka Hijau Sebagai Unsur Utama Tata Ruang Kota, Jakarta, Direktorat Jendral Penataan Ruang

Rencana Detail Tata Ruang (RDTR) Kota semarang Tahun 2000-2010. Badan Perencanaan Pembangunan daerah Kota Semarang.

Space Imaging. 2004. http://www.spaceimaging.com/products/ikonos/index.htm [22 Mei 2013]

Sugiyono. 2008. Statistika untuk penelitian, Alfabeta, Bandung.

Sutanto. 1987. Metode Penelitian Penginderaan Jauh Untuk Geografi. Makalah Ceramah Untuk Staf Pengajar UMS Surakarta. 